\title{
9. SUMMARY OF TESTING OF ODP CORING SYSTEMS ON LEG 124E 1
}

\author{
Ulrich Deutsch ${ }^{2}$
}

\section{DRILLING-FLUID CONTROL}

For mud-system control on Leg 124E, only a Marsh funnel, a mud balance, and $\mathrm{pH}$ paper were available. As the rheometer was out of order, only the weight and the $\mathrm{pH}$ level of the mud could be measured. With the Marsh funnel, one could only measure the time of the mud outflow. Therefore, the crew only had control of the change of the funnel viscosity of the drilling fluid. True viscosity determination and viscosity control were not possible. The measuring was done following mixing of the mud, resulting in no continuous control of the viscosity change. The use of drill water in combination with lost circulation (as in most ODP drilling operations) is not as critical in scientific drilling as it is in oil-field drilling.

Special mud systems are used with the diamond coring system (DCS): bentonite, some polymers, and additives such as caustic soda and soda ash in different combinations. Problems that can arise are not only those of viscosity determination, but, more important, stability control of the mud. Polymers have different sensitivities in combination with electrolytes such as $\mathrm{Na}, \mathrm{K}, \mathrm{Mg}$, and $\mathrm{Ca}$. Also, the bentonite itself is not stable against electrolytes. Therefore, problems can arise from contamination of the drilling fluid. The mud can change its rheological character. This was the case on Leg 124E.

Drilling-fluid control would be improved by the use of standard API mud-control devices like the Fann viscosimeter and the API Filterpress so that the viscosity and stability of the mud can be controlled. The effects of contamination also could be seen. A further quality control would be measuring the efficiency of the mud additives for reducing friction. This could be done with the help of a lubricity tester. In this way one can also see the influence of contamination on the efficiency of the friction reducer, so one could tell when the use of different additives is unnecessary. The measurements should be done every hour or two so that there is a continuous control; this information could be recorded in a daily mud report. Thus a document would be produced for further evaluation of the drilling fluid as well as the drilling and coring tools.

In the future, polymers other than the Minex products should be tested for ODP requirements. One example is "supermix" from DBS, which is used for coring in mining drilling and used also on the D/V Bucentaur and was tested in comparison with other additives at the Institute of Petroleum Engineering (ITE). If the polymer is used only as a friction reducer, then there may be more efficient reducers available such as Redou torque. The use of special drilling fluids would not only aid the DCS but also other systems like the navidrill coring system. In the drilling and coring process, the drilling fluid is not controlled by nature, as is the formation, but can be altered like other drilling tools. We can make further investigations in interacting with the

\footnotetext{
${ }^{1}$ Harding, B. W., Storms, M. A., et al., 1990. Proc. ODP, Init. Repts., 124E: College Station, TX (Ocean Drilling Program).

2 Shipboard engineering and scientific parties are as given in the listing of participants preceding the contents.
}

formation, using the mechanical drilling tool, the bit, and the hydraulic drilling tool, the mud.

\section{DIAMOND CORING SYSTEM (DCS)}

Considering it was the first time that the new DCS mining system was deployed on the JOIDES Resolution, it worked better in its first field test than one would expect with such a complex system. The party all became familiar with the operational aspects of the system. The most difficult and dangerous work was the handling of the guide-rail dollies during the rig-up and rig-down procedure. Improvements could be made by adding two joints to the dollies so that they could be unlatched easily from the main derrick and connected with the mining rig. This would also save a couple of hours' time.

The Longyear coring system should be modified with respect to the landing shoulder for the inner core barrel, which was drilled out because of the inner diameter of the Hydril tubing drill string. The problem arose during the loosening of the inner core barrel and unsuccessful fishing jobs. During the coring operation we were using a Huddy bit. The landing ring inside this bit was made of matrix material which was completely worn out, and therefore the inner core barrel was lost. On the Longyear bit this landing ring is made from steel that has more wear resistance, but it could not be tested on Leg 124E.

The computer installation on the platform for control of the secondary heave compensator was fine for laboratory conditions but should be better protected for rough drilling-rig application. It should be installed in a housing like that used for MWD control on rig platforms.

\section{EXTENDED CORE BARREL (XCB)}

The XCB worked properly during Leg 124E drilling operations as far as the technical functions are concerned. There were no failures with single elements of the tool, and the interaction was visible. It was possible to spud-in with the XCB into soft formations without previously using the advanced hydraulic piston corer (APC). That would be an advantage for future drilling operations in medium-hard formations where it is difficult to run the APC. In hard formations, however, the results at Site 775 showed that spudding-in with the XCB was not possible. For this purpose the positive-displacement coring motor (PDCM) should be used. As far as the coring operation is concerned, it was shown that the drilling procedure of the outer drill string is disturbing the coring process of the inner coring system. The outer roller-cone bit requires different drilling parameters than the inner diamond core bit. For efficient drilling, the roller-cone bit needs a high weight on bit (WOB) and low revolutions per minute (rpm) so that the single teeth of the roller-cone bit can overpower the threshold pressure of the formation and create a large crater volume. The diamond core bit requires, for its optimum cutting process, less WOB and higher rpm so that a rotational cutting speed between 2 and $4 \mathrm{~m} / \mathrm{s}$ can be achieved on the diamond kerf. This range, however, is much too high for the roller-cone bit and the outer drill string.

Rock destruction under a roller bit is a crushing process that destroys the rock. Core recovery using the diamond bit, which 
cuts the rock, makes for optimum core recovery. The motion of the roller bit leads to wobbling in the bottom of the hole and disturbs the smooth diamond cutting process.

All these problems increase in hard formations. This is shown in the results of drilling the interbedded chert and chalk at Site 777. Drilling into the chert with the roller bit, however, is not difficult. Core recovery and core quality were very poor, and the diamond bits were completely worn up to the steel body.

\section{NAVIDRILL CORE BARREL (NCB)}

The NCB was developed to overcome the above-mentioned weak points of the interaction between the outer drill string and inner coring system. During NCB operation, the outer drill string only passively functions as a guiding sleeve for the inner active coring system, which achieves high rpm and lower WOB for optimum diamond coring performance. The tool was used on three previous legs-114, 118, and 121-and was tested several times at ITE to evaluate the NCB potential and to eliminate the weak points by making several modifications at Eastman Christensen (EC). The tool promised to enhance the coring in difficult formations like the interbedded chalk and chert layers.

Before the tool was sent to the ship in Manila, the following modifications had been made by EC:

1. The torque segments now have an adjusting system of three springs and one set screw. On Leg 124E there was no failure with this modification.

2. The arresting part of the unlatching system consists of 12 TC balls in two rows instead of 6 steel balls in one row. This also requires two slots in the thruster adapter of the male spline and in the landing sleeve. On Leg $124 \mathrm{E}$ we had problems with the new thruster unit because the landing sleeve was not sliding during the latching procedure. This was found during a deck test. Also, changing the landing sleeve did not solve this problem. The reason was that the inner wedge of the sliding sleeve was in the middle of one ball row and not behind it where it should have been, and so it was prevented from sliding. This problem was solved by grinding the wedge to give it more tolerance.

3. In the new thruster unit is a smaller hexagonal spline, also made from steel, that also requires new tolerances on the sealing and the brass inserts. As far as the technical function is concerned, there was no problem with the new hexagonal male spline parts during Leg $124 \mathrm{E}$. However, changing the details of configuration also affects the hydraulic resistance of the tool and therefore its operational character as far as WOB is concerned. Therefore, the pressure drop is an unknown factor and makes interpretation of the pressure measurements more difficult.

4. The new brass inserts that should prevent the overstroke of the male spline were numbered. That made assembly much easier. No problems occurred with these splines during Leg $124 \mathrm{E}$, but the brass inserts may be too weak for preventing overstroke, and the dimension should be checked.

5. One of the flow dividers has four nozzles instead of three, which was previously the standard arrangement (one center and two side nozzles). The influence of the new configuration was unknown, as this flow divider was not tested on Leg 124E.

6. Instead of using the former PDM's Mach 1 and 3, we were using two modifications of the Mach 1: the Mach 1C, a 5/6-lobe PDM with smaller rotor/stator tolerances that made the motor tighter, and the Mach 1D, a 7/8-lobe motor used for drainhole drilling. In comparison with the standard Mach 1 with a U-joint shaft, both motors have a titanium flex shaft to improve one former weak point. The two motors have an increase in flow rate, maximum operating pressure, rpm, torque, and Mach 1D increased efficiency. The length of the motor was greater than the standard length. A new motor adapter was ordered by EC but did not arrive; therefore, it was manufactured on the ship. Also, the hydraulic-performance chart and the data from the EC-motor test facility were not available. All the party had was the written information received from EC during a visit in Celle. Thus we were not sure if these data are true or not. The only conclusions we could reach from the results on Leg $124 \mathrm{E}$ are that the Mach 1D did work and the Mach 1C did not. The fact that the crew could turn the Mach $1 \mathrm{C}$ driveshaft with a wrench on deck did not mean that the motor was working properly.

The weakest point that occurred was the failure of one Belleville spring in the unlatching system of the thruster unit. The same spring was used several times before without any failure. First, it may help to replace the spring after every two or three runs, but this is no guarantee of preventing further failures. The problem is not only breakage of the spring itself, but most of all that the tool can get stuck in the double-window latch sleeve of the outer drill string, which makes it impossible to pull out of the ODP bottom hole assembly. Therefore, one should think about a new design for the dampening and unlatching system. This can be ordered from EC for manufacturing and testing under required conditions at ITE. The compressed spring is also dangerous during handling because it can suddenly expand and injure someone whose hand is at the sliding sleeve.

The drilling operations at Site 777 showed that the NCB is better in coring difficult formations than the XCB. The coring process could be improved by making full use of NCB potential. With development of the NCB, the hardware of an independent inner coring system would be available. The hardware can be improved by the above-mentioned ways. To make full use of the hardware in coring operations for ODP requirements, the application of the NCB must be improved. Therefore, tool performance must be evaluated more fully. The drilling operation at Site 777 showed that we could not make use of the Leg 114 operation chart. This is not surprising, because many hardware modifications were made that changed the tool's hydraulics completely. The tool itself is operated hydraulically, which means that the only parameter changeable is the flow rate, and the only parameter measurable is the standpipe pressure (system pressure of rotary hose, drill pipe, drill collars, thruster unit with nozzles, motor with different torque and therefore of changing responding pressure, flow divider, core barrel, bit, and borehole annulus). Therefore, if we don't know the single pressure drops of these hydraulic resistances that are switched in series, we can't correlate and interpret the measured pressure in the standpipe. The only steering parameter of the tool is the flow rate. By increasing the flow rate, we directly increase the rpm in the PDM and at the same time increase the WOB by changing the pressure drops in the thruster nozzle sub. Both can lead to a higher torque and therefore again to a higher pressure drop in the PDM. Also, the pressure drop in the other tool parts will increase with increasing flow rate. If the flow rate and the pressure drop of every system part can be correlated, one could directly see higher torque by measuring the pressure increase, and one could see when the stall moment of the motor is reached. Also, one could not estimate the WOB with the nozzle configuration and the increase of bit force during higher flow rates.

For optimum NCB performance, a new operation chart is needed for the hardware before it is sent to the ship. This could be done by hydraulic flow rate and pressure measurements of every tool part and the whole system plus torque and rpm measurements at the motor. The motor-performance tests can be done at the EC facility but should be supervised. The hydraulic tests, with load-cell tests to get the pressure-WOB correlation and additional drilling tests, can be done at ITE. By now the crew can also test every detail of the tool and the interaction of all parts of the system to make sure that the tool will work properly on the ship so that no time is lost through trial and error. 
For some special parts like the springs, one can also conduct fatigue-failure tests.

Some problems also occurred at Site 777 during core jamming. One possibility is that during the change from the hard to the soft layer the hard core is inside the core catcher and cannot be lifted by the underlying soft material and is therefore ground with the bit kerf onto the soft material. This problem could be avoided by the use of another core catcher like the basket-type catcher.

The problem with the face-discharge system of the used pilot bits was plugging of the mud ports. This problem could be solved with a new bit design and optimum bit hydraulics.

All the bit and core-catcher tests could be done at ITE with the Longyear mining rig while drilling in different types of rock. By doing such test programs before field operations, unnecessary delay could be avoided and the field tests made more intensive. Most of all, we should make new operation charts regarding the tool modifications in order to make full use of the NCB, so it will result in satisfactory core recovery.

During default of an operation chart for Leg 124E, the WOB was only guesswork in interpreting the results from the measured pressure. The bit damage in Hole 777B occurred by using $14 / 14$ nozzles in the thruster unit (always $11 / 11 / 18$ in the flow divider). This could have been caused by a manufacturing error or by too much WOB. Therefore, we changed to the $16 / 16 \mathrm{noz}$ zle in Hole $777 \mathrm{C}$ but the same bit disaster resulted. Both bits were Christensen mining bits. Then we used an Eastman-Christensen bit with the $16 / 16$ nozzles in Hole 777D. The diamonds on the bit surface were partially broken out. This can be either a sign of too high WOB or the result of impact on a hard layer after unlatching. Because there were no more EC bits available, the crew used impregnated pilot bits with $20 / 20$ nozzles. In the two runs the diamond grit had shown a good exposure with the $20 / 20$ nozzles. That was a sign that the WOB is in the recommended range. The actual level of WOB is, however, just guesswork. If we extend the old operation chart to the new flow-rate range of the motors, and assume that the EC data are true, then we would be in the range of about 1000 to $1500 \mathrm{~kg}$. WOB. With a diamond set area of $40 \mathrm{~cm}^{2}$ we get a specific axial force of 200 to $400 \mathrm{~N} / \mathrm{cm}^{2}$, which relates to the lower level of WOB.

In Hole $777 \mathrm{E}$, the new thruster unit with other hydraulic properties was used. The bit was now a surface-set pilot type with a combination of $11 / 11 / 16$ nozzles in the flow divider and $14 / 14$ and then $14 / 20$ in the thruster unit. The bit itself was in good condition, but this did not provide enough information for WOB determination and no information about the correlation between nozzle diameter and WOB.

Future development should therefore lead to better control of the drilling operation. The first step had already been done with the dipstick so that we could measure any penetration at all. This is, however, possible with the dipstick only after re- trieving the NCB. An improvement would be to measure the penetration during drilling so that controlling and steering the coring operation by changing the flow rate would be possible. A first simple method would be just to add two fingers to the thruster nozzle sub (similar to the torque segments). During penetration, the finger will expand into slots that are turned, for example, every $20 \mathrm{~cm}$ into the outer drill string along the part where the hexagonal mandrel will move downward. In the short moment that the finger expands, it would conform to the open diameter of the nozzles. This would result in a short pressure increase and would be measured in the standpipe and recorded with the penwriter. In this way we could measure the penetration by adding the pressure peaks, and together with the paper speed of the penwriter, we would have the rate of penetration. This pressure pulse is the principle of MWD tools, but no sensitive electronic device is needed. Further potential is given by the sonar coring monitor from DBS. The system could not be tested during Leg 124E, but its addition could be a big step forward. DBS also mentioned that they will develop the SCM with an MWD-module so that the data would be available not only afterward, with the help of a memory chip, but also in a real-time mode so that the steering of the process is possible. This would make enhanced NCB application possible in the future.

A further possibility, especially for hard and interbedded formations, would be the use of a downhole hammer driven by the circulated mud. The hammer would be installed between the navidrill and the core barrel. The hammer requires fewer rpm, which would lead to a low-speed motor and less WOB with less torque, so that the number of stages in the motor can be reduced and the thruster section shortened.

As far as the operation of the NCB is concerned, the outer drill string should not be turned during NCB penetration because, as mentioned above, the wobbling of the roller-cone bit disturbs the diamond coring.

\section{LAST, BUT NOT LEAST}

The results of engineering Leg $124 \mathrm{E}$ offer a broad potential for future development. From a technical point of view, it was a very intensive leg, and the international information interchange and cooperation will promote good possibilities for the future. The DCS opens new ways of diamond coring in deep-water applications and got us off to a good start. The NCB is on the way to optimum performance and will be the basis for future ODP development. With the help of these tools, ODP's high coring standards can be achieved, thus helping to achieve the scientific goals of the program.

I thank all ODP staff members for their help and their patience. We look forward to future cooperation.

Ms 124E-109 